\title{
PENSIONES: DESMENUZANDO EL SEGUNDO ANUNCIO PRESIDENCIAL
}

Por Fernando López, Ph.D. en Finanzas, Washington University in St. Louis, Estados Unidos. Académico FEN UAH.

El 9 de agosto del año 2016, la Presidenta de la República, en cadena nacional, convocó a un acuerdo entre distintos sectores políticos con el objeto de mejorar nuestro sistema de pensiones. A menos de un año de este llamado, el 12 de abril pasado, también en cadena nacional, la Presidenta anunció la elaboración de una propuesta de reforma que surge como resultado de este proceso de diálogo liderado por el Ministerio de Hacienda. El presente artículo describe las principales medidas anunciadas y analiza su posible impacto.

La primera medida consiste en un aumento de $5 \%$ en la cotización individual con cargo al empleador. Tres puntos porcentuales de este aumento estarian destinados a una cuenta individual del trabajador, los cuales serian de su plena propiedad y heredables. El $2 \%$ restante iria a un seguro de ahorro colectivo que se distribuiria con criterios de solidaridad inter-generacional e intra-generacional, sin que se detalle aún el mecanismo de distribución de estos recursos. Esta medida se implementaría gradualmente en un periodo de 6 años. Considerando el aumento en la expectativa de vida y el bajo nivel de ahorro que alcanzan los afiliados al momento de la jubilación, un aumento en la cotización es una medida que contribuye a mejorar nuestro sistema de pensiones.

Respecto a su posible impacto, el anuncio señala que estos recursos permitirian aumentar en $20 \%$ las pensiones de los actuales pensionados del sistema de AFP y en 50\% las pensiones futuras de los actuales cotizantes al momento de su jubilación, cuando el sistema esté en pleno funcionamiento. Sin embargo, al considerar las estimaciones presentadas en un estudio publicado en el Observatorio Económico de diciembre de 2016 (López, 2016), los efectos de esta medida serian inferiores a los anunciados.

Considerando los datos y supuestos de dicho estudio, para aumentar en 50\% las pensiones futuras de los cotizantes que ingresen al sistema cuando éste se encuentre en pleno funcionamiento sería necesario que los cinco puntos de mayor contribución vayan íntegramente a sus cuentas de capitalización individual (o que sea distribuido exclusivamente entre quienes aportaron dichas cotizaciones). En otras palabras, éste impacto
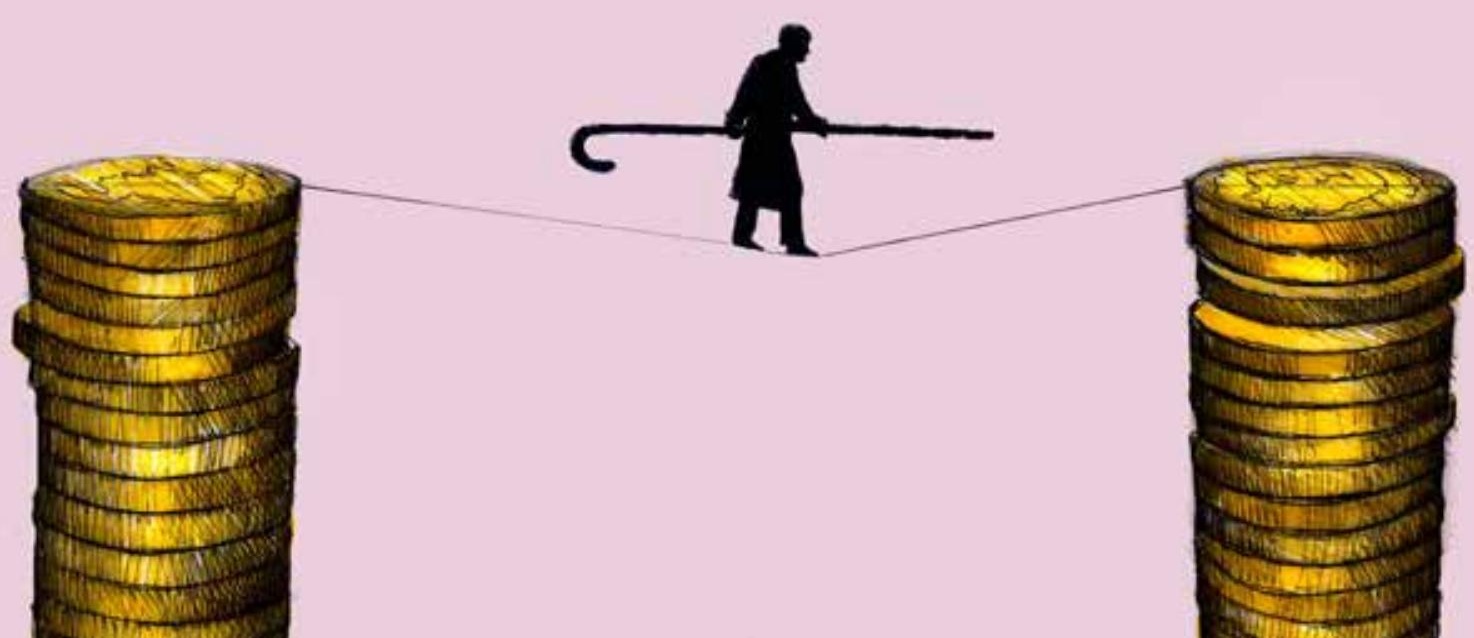
es incompatible con la idea de destinar dos puntos de la mayor cotización a un seguro de ahorro colectivo con el que se quieren mejorar las pensiones actuales.

El aumento de $3 \%$ en las cotizaciones individuales permitiria aumentar en $30 \%$ las pensiones de los trabajadores que se integren al sistema cuando éste se encuentre en pleno funcionamiento. Para los trabajadores que tengan 40 años al momento de la aplicación de esta medida, el impacto se reduce a $11 \%$ y a menos de 6\% para quienes tengan 50 años de edad.

Por otra parte, para aumentar en 20\% las pensiones de los actuales pensionados del sistema de AFP, la reforma deberia destinar 1,4 puntos porcentuales de los dos que irian al seguro de ahorro colectivo, con lo cual solo quedaría $0,6 \%$ disponible para financiar pensiones futuras. En este contexto, el aumento en las pensiones futuras de los cotizantes dependerá de la manera en que se distribuya este $0,6 \%$. El máximo impacto de la mayor cotización en las pensiones futuras de los cotizantes seria 36\% para los trabajadores que se integren al sistema cuando éste se encuentre en pleno funcionamiento y los 0,6\% sean destinados a las cuentas de capitalización de los cotizantes.

Por último, es importante señalar que destinar una parte del $5 \%$ a un seguro de ahorro colectivo tiene dos inconvenientes. Primero, aumenta los incentivos de los trabajadores para subdeclarar ingresos y operar en la informalidad, deteriorando sus condiciones laborales. Segundo, es un impuesto regresivo que lo pagan los trabajadores dependientes (asalariados) y, en mayor proporción, aquellos que ganan menos del tope imponible.

La segunda propuesta consiste en delegar la administración de este $5 \%$ a una entidad pública y autónoma, y según el anuncio, "con reglas estrictas y altas exigencias profesionales, para que nadie pueda poner en duda su eficiencia, transparencia e independencia." Esta medida apunta a darle mayor legitimidad al sistema, permitiendo que la administración de los fondos de pensiones se realice a través de entidades privadas y estatales, como ocurre en otros sectores económicos como la banca. Sin embargo, una desventaja del diseño planteado es que aumenta el costo de administración de los fondos previsionales y no contribuye a promover la competencia en la industria. En efecto, las AFPs actuales no necesitarian aumentar sus comisiones para asumir la administración de un fondo de mayor tamaño, pese a que esto les generará un mayor costo asociado a un mayor requerimiento de encaje y una mayor carga administrativa. Dos estudios recientes sugieren que si la propuesta hubiese contemplado la creación de una entidad pública que compitiera por el total de los fondos administrados, se podría converger a una situación en la cual los cotizantes pagan menos en una industria con un mayor grado de legitimidad. ${ }^{1}$

El tercer conjunto de medidas apunta a darle mayor legitimidad al sistema por la vía de una mayor participación ciudadana. Específicamente, el anuncio plantea permitir la participación de afiliados en la definición de las políticas de inversión, politicas de solución de conflictos de interés y la elección de directores en las empresas en que se invierten los fondos de pensiones. La principal ventaja de esta medida es que podría contribuir a fortalecer la percepción de propiedad de los fondos de pensiones por parte de los afiliados. Sin embargo, dado que la complejidad de las decisiones consideradas excede de manera significativa las habilidades del afiliado promedio para comprender y analizar problemas financieros, estas medidas dificilmente mejorarán la rentabilidad de los fondos de pensiones, el capital humano de los directorios o reducirán la incidencia de eventuales conflictos de interés. Dependiendo del grado de poder que se traspase a los afiliados, estos podrian incluso promover iniciativas que afecten negativamente la rentabilidad de los fondos de pensiones. En este contexto, la propuesta de crear un Comité de Propietarios para cada AFP permitiria aumentar la participación de los afiliados evitando estos problemas². Especificamente, la función principal de dicho Comité sería encargar a expertos evaluaciones sobre la calidad de los servicios prestados por cada administradora a sus afiliados, incluyendo la gestión financiera, los servicios administrativos y las comisiones cobradas. De esta manera, los afiliados podrán expresar sus visiones sobre la base de estudios técnicos.

Por último, el proyecto propone crear mecanismos e incentivos para que el cobro de las comisiones esté relacionado con los beneficios reportados a los afiliados porque, según el anuncio, "no es posible que cuando a un administrador le vaya mal, el único que asuma el costo sea el afiliado." Según declaraciones públicas del actual Superintendente de Pensiones, se definirán índices de referencia para los distintos multifondos y un esquema de comisiones en que las administradoras recibirán un premio o castigo cuando sus rentabilidades sean mayores o menores a estos indices de referencia, respectivamente. Sin conocer los detalles de este esquema de premios y castigos, es dificil analizar el posible impacto que podría tener esta medida en las estrategias de inversión de las AFPs. Sin embargo, mientras mayor sea el castigo por alcanzar rentabilidades inferiores a estos indices, lo más probable es que las administradoras traten de replicar sus rentabilidades y asi eviten el pago de la penalización.

Respecto al posible impacto de esta medida en las pensiones, el resultado es incierto. Por una parte, hay quienes plantean que la gestión "activa" de las AFP permite acceder a combinaciones de rentabilidad y riesgo superiores a las que se obtendrian siguiendo estrategias pasivas, replicando índices. Sin embargo, no hay estudios académicos recientes que cuantifiquen dicho valor agregado. La evidencia internacional respecto al desempeño de los gestores de fondos institucionales tampoco responde esta pregunta porque sus resultados son mixtos. Sin estos estudios de desempeño, no es posible determinar si esta medida permitirá o no aumentar las pensiones futuras ni su magnitud. Sería aventurado implementar un esquema de indices de referencia sin un estudio de desempeño previo, cuyo costo es marginal en relación a los US\$ 180 mil millones de dólares que administran las AFP.

'López, F. (2016). Aumento de 5\% en la Cotización Previsional y su Impacto en las Pensiones, oe, N111, UAH. López, F. (2017). Estructura de propiedad, legitimidad y competencia en la industria de AFP: Una mirada financiera. Gestión y Tendencias, 2(2), 14-19. Saavedra, E. (2017). Lucro, propiedad y eficiencia económica en el mercado de AFPs. Gestión y Tendencias, 2(2), 10-13. ${ }^{2} V a l d e ́ s, ~ S . ~(2017)$. Un comité de propietarios para cada AFP. Gestión y Tendencias, 2(2), 3-6. 